\title{
Mikrobilgisayar Tabanlı El-Bilek Damar Örüntüleri Kullanılarak Biyometrik Kimlik Doğrulama İşleminin Yapılması
}

\author{
${ }^{* 1}$ Ömer Faruk Boyraz, ${ }^{1}$ Muhammed Ali Pala, ${ }^{1}$ Murat Erhan Çimen, \\ ${ }^{1}$ Ali Fuat Boz, ${ }^{1}$ Mustafa Zahid Yildız \\ ${ }^{1}$ Teknoloji Fakültesi, Elektrik Elektronik Mühendisliği, Sakarya Uygulamalı Bilimler Üniversitesi, Sakarya, Türkiye
}

\section{Özet:}

Damar tanıma sistemleri, insanları damar yapılarına göre ayırabilen bir biyometrik tanıma biçimidir. El-bilek damar deseninden kimlik tanıma da bu sistemlerden birisidir. Bu çalışmada $850 \mathrm{~nm}$ dalgaboyuna sahip kızılötesi ışık kaynağı kullanılarak kişilerden alınan el-bilek damar görüntüleri çeşitli görüntü işleme algoritmalarından geçirilerek segmente edilmiştir. Segmentasyonu sağlanan görüntülerden anahtar nokta çıkarımı işlemi için ölçekten bağımsız öznitelik dönüşümü (SURF) yöntemi kullanılmıştır. SURF yöntemi ile elde edilen öznitelikler dönme, kamera açısı, ortamın 1şık şiddeti vb. durumlara karşı değişmez olduğu için bu yöntem tercih edilmiştir. Kimlik tespiti işleminde ise çıkarılan anahtar noktalardan faydalanılarak öklid mesafesi yönteminden yararlanılmıştır. Veritabanındaki el-bilek damar örüntüleri kullanılarak yapılan eşleştirme işlemleri sonucu doğruluk oranı \%97 olarak tespit edilmiştir.

Anahtar Kelimeler: El-bilek, kimlik doğrulama, kızılötesi damar görüntüleme, öznitelik çıkarımı, surf

\section{A Microcomputer-Based Biometric Authentication System Using Hand-Wrist Vein Patterns}

\begin{abstract}
:
Vein recognition systems are a form of biometric recognition that can discriminate people according to vascular structures. Authentication from the hand-wrist vein pattern is one of these systems. In this study, hand-wrist vein images taken from subjects via an infrared light source with $850 \mathrm{~nm}$ wavelength were passed through various image processing algorithms and segmented. Speeded up Robust Features (SURF) method was used for key point extraction from segmented images. Attributes obtained by SURF method include rotation, camera angle, light intensity, etc. This method is preferred because it is invariant to the situations. In the identification process, euclidean distance method was used by utilizing the extracted key points. Accuracy rate was found to be $97 \%$ as a result of verification procedures using hand-wrist vein patterns in the database.
\end{abstract}

Key words: Hand-wrist, authentication, near-infrared vein imaging, feature extraction, surf

*Corresponding author: Ömer Faruk BOYRAZ Address: Faculty of Technology, Department of Electrical and Electronic Engineering Sakarya University of Applied Sciences, 54187, Sakarya TURKEY. E-mail address: omerboyraz@subu.edu.tr, Phone: +902642950302 


\section{Giriş}

Biyometri; insanların parmak izi, iris, yürüyüş şekli, hareket biçimleri gibi çeşitli insan fizyolojik ve davranışsal özelliklerine göre kişileri tanımlamayı sağlar. Parmak izi, avuç içi izi, iris, gibi fizyolojik özellikler vücudun şekli ile ilgiliyken ses, el yazısı imzası ve yürüyüş gibi davranışsal özelliklerse bireyin davranış modeliyle ilgilidir. [1-2]

Çeşitli biyometrik özellikler arasında, damar biyometrisi, damar deseninin kişiden kişiye benzersiz olması cildin içinde bulunmasından dolayı kopyalanmasının zor olması ve temassız şekilde doğrulama işleminin yapılabilmesi gibi avantajlara sahip olduğu için hızla popülerlik kazanmıştır. Bu gerçek, özellikle bankacılık uygulamalarında damar biyometrik sisteminin konuşlandırılmasını sağlamıştır. Bankacılık uygulamalarında özellikle avuç içi kimlik doğrulama işlemleri kullanılmaktadır. Bu sistemlerde avuç içi, bir platforma yerleştirilir ve kişinin damar örüntüsünden kimlik tespiti gerçekleştirilir. Yüzey alanına yapılan temas platformun zamanla kirlenmesine ve damar örüntüsünün kamera tarafından algılanamamasına neden olabilmektedir. Bu yüzden temassız kimlik doğrulama sistemlerinin yaygınlaşması hem daha steril hem de zamanla yüzey alanına bağlı oluşan kirlenmelerden ötürü kimlik doğrulamadaki hataların minimize edilmesini sağlayabileceği öngörülmektedir.

Yakın kızılötesi dalgaboyunun kandaki hemoglobin tarafından soğurulması ile cilde yakın damar bölgelerinin kızılötesi kamerada daha koyu bir şekilde görüntülenmesi neticesinde damar ağ yapısı belirlenmiş olur [3].

Damar örüntüsünden kimlik tanıma işlemi; el üstü damar örüntüsü [4], parmak damar örüntüsü [5], avuç içi damar örüntüsü [6] ve bilek damar örüntüsü [7] gibi çeşitli görüntüler üzerinden yapılabilmektedir. Dört farklı damar kalıbı çeşidi arasında el-bileği damar ağ yapısı dış cilde çok yakın konumlanmış olması ve yoğun bir şekilde bulunmasından ötürü net bir görüntü sağlamaktadır.

El bileği damar biyometrisi literatürde çok fazla araştırılmamıştır. Akhloufi ve arkadaşları yaptıkları çalışmada ön-kol bilek bölgesindeki damar ă̆ yapılarını CCD kızı̈ötesi kamera vasıtasıyla elde etmişlerdir. Elde edilen görüntülerin kontrastını iyileştirmek için anizotropik difüzyon işlemi uygulanmış ardından morfolojik işlemler kullanarak damar ağ yapılarını segmente etmişlerdir [8]. Pascual ve arkadaşları tasarladıkları aydınlatma sistemi ve kızılötesi kamera platformu sayesinde el-bilek damar görüntüleri toplamış ve bu görüntülerin kimlik tanımada kullanılabilecek netlikte olduğunu göstermişlerdir [9]. Kurban ve arkadaşları yaptıkları çalışmada, 5 MP çözünürlüğe sahip bir cep telefonu kamerası 14 kadın, 20 erkek gönüllüden günün farklı zamanlarında üçer tane el-bilek damar görüntüsü toplamışlardır. Damar bölgelerinin görünürlügünün arttırılması amacıyla görüntülere sırasıyla çeşitli görüntü işleme adımları uygulanmıştır. İlk olarak görüntülere FFT tabanlı alçak geçiren filtre uygulanmış ve bu sayede arka plan gürültüleri elimine edilmiştir. Sonrasında keskinleştirme (sharpen) filtresi ve histogram eşitleme işlemleri uygulanarak damar bölgeleri netleştirilmiştir. Son olarak görüntüler işlem süresini azaltmak için 1/5 oranında yeniden boyutlandırılmıştır. Çeşitli sinir ağları kullanılarak eğitilen sistemde doğruluk oranı SVM (Support Vector Machine) yöntemi ile \%96.07 olarak tespit edilmiştir. [10] 
Yaygın olarak, damar tanıma teknolojisi sırasıyla şu adımları içerir; görüntü elde etme, damar görüntüsü önişleme, damar görüntü özelliği çıarma ve gösterimi, sınıflandırıcı tasarımı ve tanıma. Pratikte en önemli ve zor olan kısım, etkili bir özellik çıkarma yönteminin geliştirilmesidir.

Bu çalışmada önerilen düşük maliyetli yakın kızılötesi tabanlı bir kimlik tanıma sistemidir. Elbilek damar görüntülerinden kimlik tespiti çalışmasında ilk olarak çeşitli görüntü işleme yöntemleri kullanılarak damar ağ yapısı segmente edilmiştir. Sonrasında işlenen görüntüler üzerinde öznitelik çıkarımı için SURF yöntemi kullanılmıştır. Daha sonra eşleştirme adımında ise çıkarılan öznitelikler arasındaki benzerlik, öklid mesafesi kullanılarak belirlenmiştir.

\section{Materyal ve Yöntem}

\subsection{Materyal}

Çalışmada kullanılan 20 bayan 30 erkek toplam 50 gönüllüden alınan sağ ve sol el bilek damar görüntüleri şekil 1'de gösterilen düzenek sayesinde toplanmıştır. $850 \mathrm{~nm}$ dalga boyuna sahip kızılötesi power ledler ile aydınlatılan el yerleştirme platformuna kişilerin bileklerini yerleştirmeleri istenmiştir ve $15 \mathrm{~cm}$ yükseklikten kızılötesi kamera vasıtasıyla görüntüler alınmıştır. Prosedürler katılımcılara herhangi bir zarar vermemiştir. Tüm katılımcılar yazılı onay vermiş ve deneyler Sakarya Üniversitesi Tip Fakültesi Etik Kurulu tarafından onaylanmıştır (no.71522473/050.01.04/341).

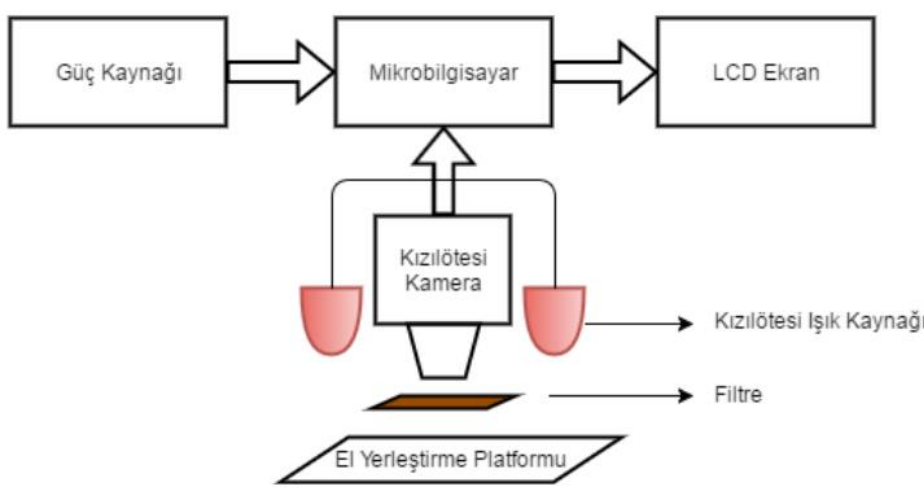

(a)

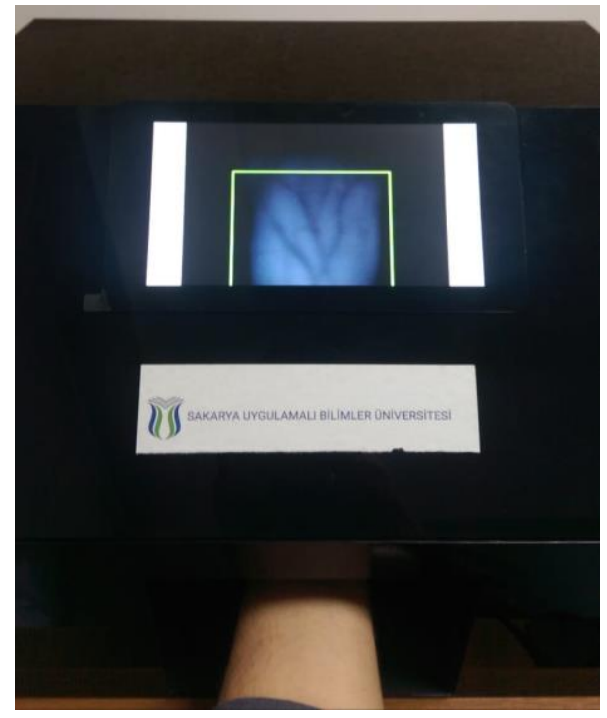

(b)

Şekil 1. (a) Sistemin kurulum mimarisi [11] (b) El-bilek görüntülerinin toplanma aşaması

Elde edilen görüntüler mikrobilgisayarda sayısal ortama aktarılmış sırasıyla görüntü işleme ve öznitelik çıkarım algoritmalarına sokulmuştur. Çıkarılan öznitelikler daha sonra yakın-gerçek zamanlı kimlik doğrulama işleminin yapılabilmesi için mikrobilgisayar ortamındaki veritabanında saklanmıştır. 


\subsection{Yöntem}

Yerel özellik tabanlı el-bilek görüntülerinden kimlik doğrulama sisteminin akış şeması Şekil 2'de gösterilmiştir. Sistemin kayıt aşamasında, kızılötesi kamera yardımıyla alınan el-bilek damar görüntüleri sırasıyla gri seviye dönüşümü, kontrast sınırlı adaptif histogram eşikleme, medyan filtreleme, adaptif eşikleme ve morfolojik işlemlerden geçirilerek SURF algoritmasına sokulmuştur. SURF algoritmasına giren görüntüler üzerinden anahtar noktalar çıkarılarak veritabanına kaydedilir.

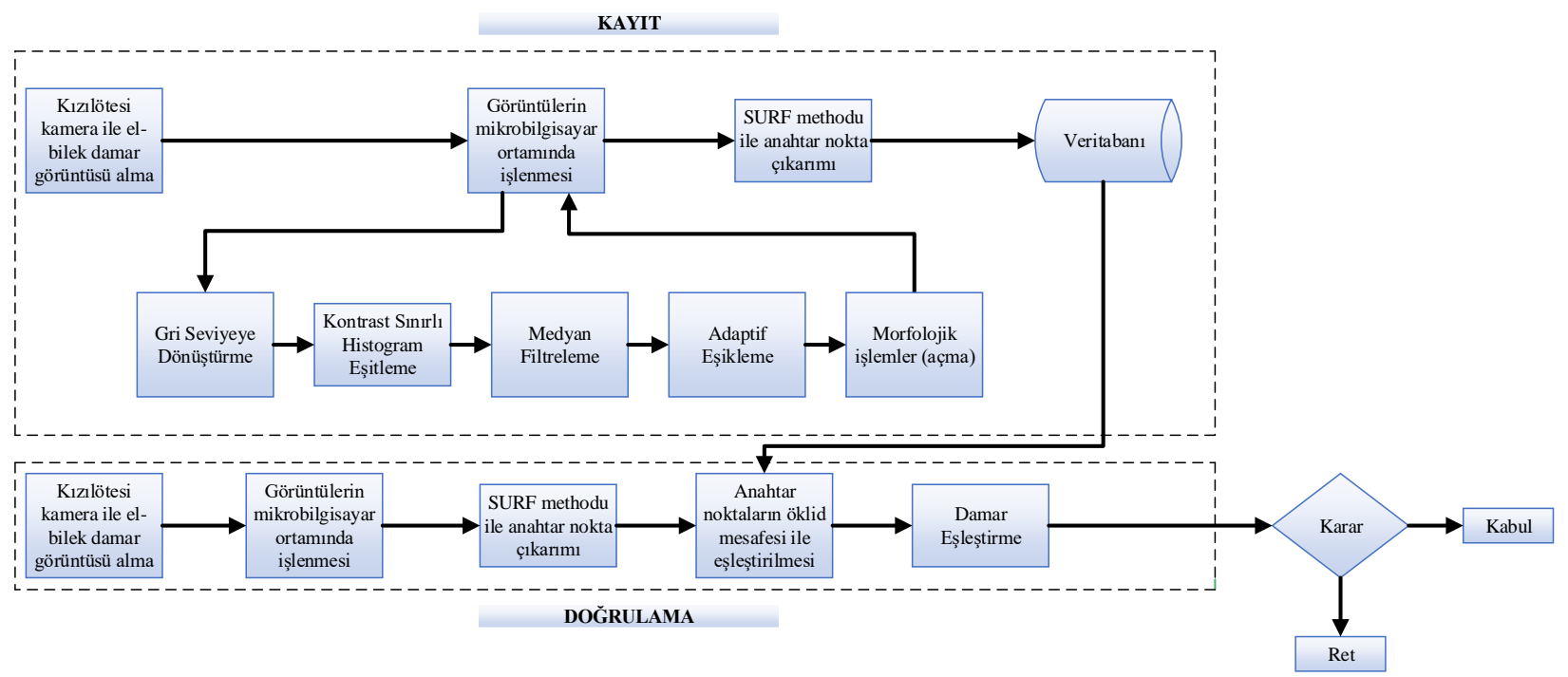

Şekil 2. El-Bilek Damar örüntüsünden kimlik tanıma sisteminin genel çerçevesi.

Doğrulama adımında ise kamera tarafından alınan gerçek zamanlı el-bilek damar görüntüsü, görüntü işleme adımlarından tekrar geçirilir ardından işlenen görüntü üzerinde anahtar nokta çıkarma işlemi gerçekleştirilir. Ardından, veritabanına daha önce kaydedilmiş görüntülerin anahtar noktaları ile yeni görüntünün anahtar noktaları eşleştirilir. İşlemler sonucunda en fazla eşleşme noktasına sahip iki görüntü aynı olarak kabul edilmiştir. Şekil 2'de gösterilen blok diyagramdaki işlemler sırasıyla aşağıdaki bölümlerde açıklanmıştır.

\subsubsection{Görüntü Issleme Algoritmalart ile Damar Bölgelerinin Segmente Edilmesi}

İlk ön işleme adımında görüntüler üzerinde gri seviye dönüşümü, kontrast sınırlı adaptif histogram eşitleme (KSAHE), medyan filtreleme ve adaptif eşikleme işlemleri uygulanmıştır. Ardından damar bölgesinin görünürlüğünü arttırmak için gri seviye dönüşümü yapıldıktan sonra görüntülere KSAHE işlemi uygulanmıştır.

El-bilek damarındaki kontrast iyileştirilmesi tüylü bölgeye sahip kişilerde gürültüye neden olur. $\mathrm{Bu}$ sorunun üstesinden gelmek için, medyan filtresi uygulanmıştır. Medyan filtrelemeden sonra, damar görüntüleri adaptif eşikleme ile 1 bit'e dönüştürüldü. Son olarak 1 bite dönüştürülmüş görüntüler üzerinde morfolojik işlemler uygulanarak gürültülerin elimine edilmesi ve sonrasında damar bölgelerinin segmente edilmesi sağlanmıştır. Tüm görüntü işleme adımları, Şekil 3 'te 
gösterilmektedir. Şekil 3.a, ham görüntüyü gösterir ve Şekil 3.f, 1 bit'e dönüştürülen ve morfolojik olarak işlenmiş damar bölgesini gösterir.

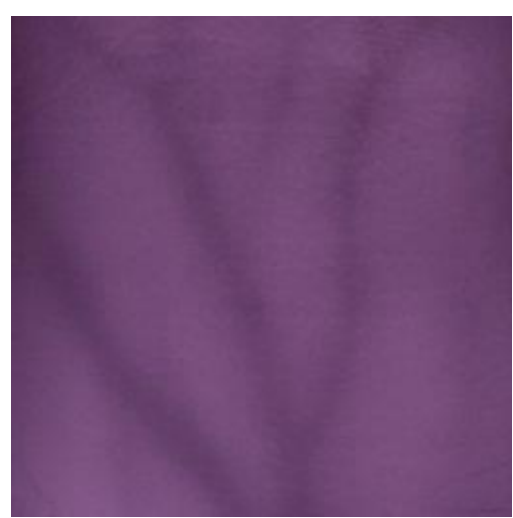

(a)
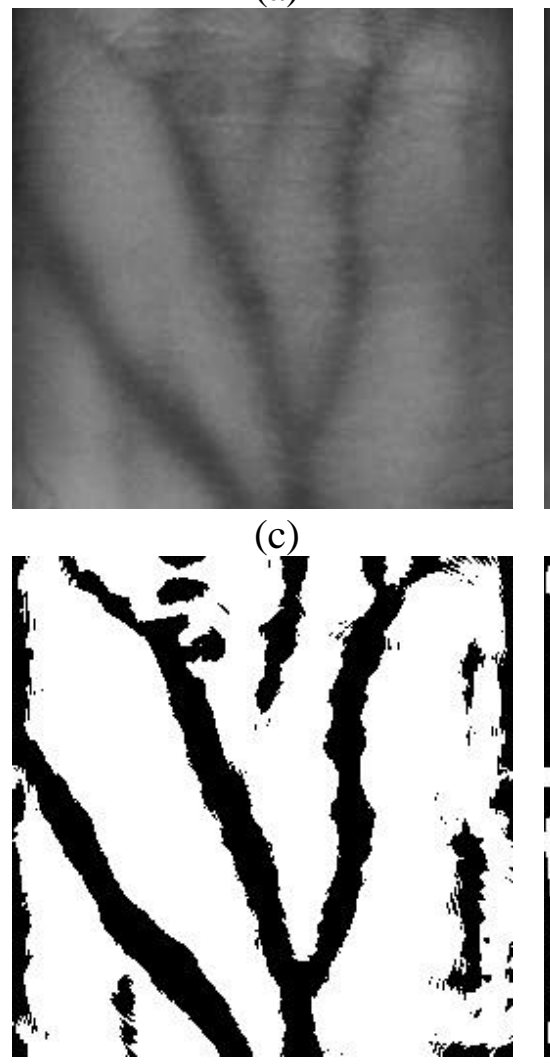

(e)

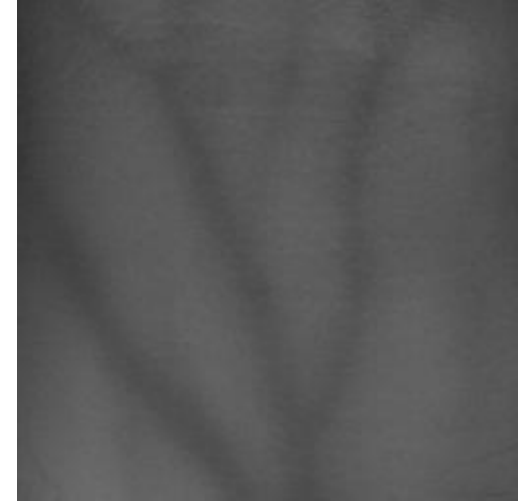

(b)

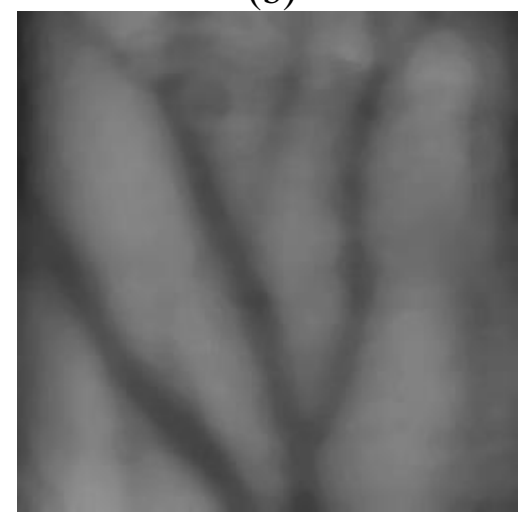

(d)

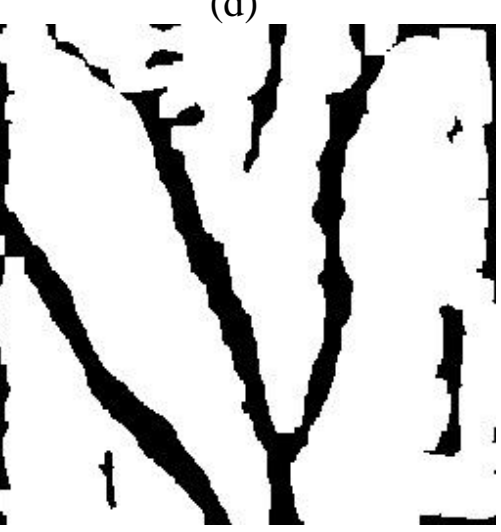

(f)

Şekil 3. (a) Ham görüntü (b) Gri seviyeli (c) KSAHE (d) Medyan (e) Adaptif eşikleme (f) Morfolojik işlemler sonras1

\subsubsection{SURF Algoritmasl}

SURF, (Speeded-up Robust Features) Hessian matrisinin determinantını kullanarak özellik noktalarını tespit eder [12]. 
$H(X, \sigma)=\left(\begin{array}{ll}L_{x x}(X, \sigma) & L_{x y}(X, \sigma) \\ L_{y x}(X, \sigma) & L_{y y}(X, \sigma)\end{array}\right)$

Burada L, Gaussian ikinci mertebenin X (x, y) noktasında ölçeğin $\sigma$ cinsinden ve Lxy ve Lxy için benzerlikle türetilmesidir. Sınıflandırma için fonksiyonun maksimum ve minimum diskriminant değeri kullanılır. Tanımlama, algılanan özellik noktasının etrafındaki pencerenin oluşturulmasıyla başlar. Bu bölgedeki pikselden sonuçlanan özellik vektörü hesaplanır. Şekil 4'te damar bölgesi segmente edilmiş ve morfolojik işlemlerden geçirilmiş el-bilek damar görüntüsü üzerinden SURF methodu kullanılarak anahtar nokta çıkarım işlemi gösterilmiştir.

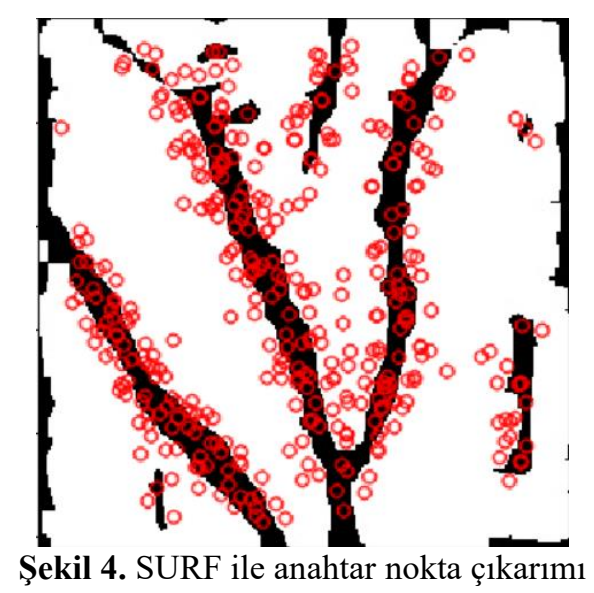

\section{Sonuçlar}

SURF yöntemi yardımıyla, el-bilek görüntüleri üzerinde olan anahtar noktalar ve bu noktaların tanımlayıcıları tespit edilir. Aynı işlem, sonradan kimlik tanıma işlemi sırasında kameraya gelen tüm elemanlara uygulanır. Veritabanındaki görüntüler ile kamera önüne gelen görüntülerin anahtar noktaları karşılaştırılarak eşleştirme yapılır. Şekil 5'te örnek bir eşleştirme işlemi gösterilmiştir. Eşleştirme işlemi anahtar noktalar arasındaki Öklid mesafesi yöntemi kullanılarak yapılmıştır.

mesafe $=\sqrt{\left(x(i)-\left(\text { sütun }+x_{2}(i)\right)^{2}+\left(y(i)-y_{2}(i)\right)^{2}\right.}$

Denklem 2 de iki görüntü arasında bulunan eşleştirme öncesi mesafelerinin bulunması işlemi yapılmaktadır. Denklemde görülen $x(i)$ ve $y(i)$ veri tabanında bulunan görüntü üzerindeki anahtar noktaların x-ye eksenlerindeki noktasal konumunu göstermektedir. Şekil 5 'te örnek bir eşleştirme işlemi gösterilmiştir. Şekil 5 (a)'da eşleştirme işlemi için gerçek zamanlı alınan görüntünün işlenmiş hali görülürken (b)'de ise aynı kişiye ait bilek damar görüntüsünün veritabanında kaydedilmiş hali görülmektedir. Kişiye ait el-bilek görüntüleri başarılı bir şekilde eşleşmiştir. 


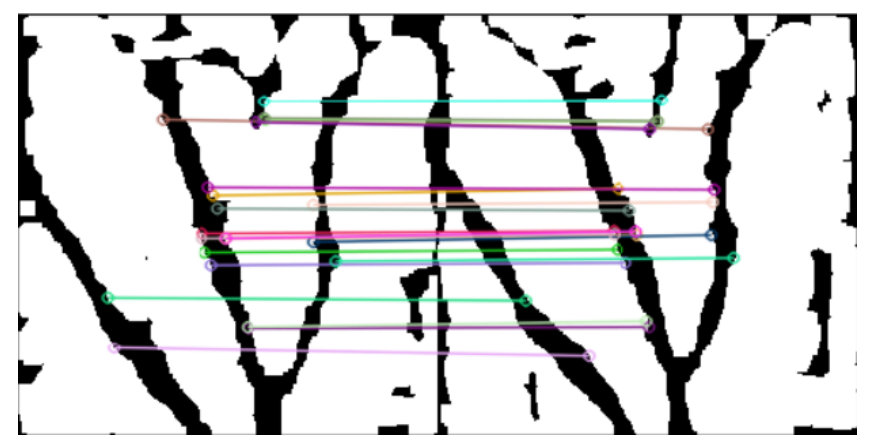

(a)

(b)

Şekil 5. SURF yöntemi ile eşleştirme işlemi (a) Kameradan gerçek zamanlı alınan görüntü (b) Veri tabanında bulunan görüntü

Çalışma neticesinde segmentasyonu yapılan el-bilek görüntüleri üzerinde yapılan eşleştirme sonucu doğruluk oranı \%97 olarak belirlenmiştir. Eşleştirme işlemi süresi ise her bir denek için 100 kişilik veritabanında yaklaşık 4 saniye kadar sürmüştür.

\section{Tartışma}

Yapılan çalışmada mikrobilgisayar tabanlı el-bilek damar görüntülerinden kimlik tanıma işlemi yapılmıştır. Raspberry Pi kızılötesi kamerası ve 3 B + mikrobilgisayarı kullanılarak yapılan çalışma neticesinde 100 kişiden toplanan el-bilek damar görüntüleri mikrobilgisayar ortamına aktarılmış ve çeşitli görüntü işleme algoritmalarından geçirilerek damar bölgeleri segmente edilmiştir. Damar bölgeleri görünür hale gelen görüntüler yerel özellik çıkarımı için SURF algoritmasına sokulmuştur. Anahtar noktaları çıkarılan görüntüler veritabanında saklanmış ve sonrasında kamera önüne gelen damar görüntüleri ile eşleştirme işlemi yapılmıştır.

\section{Teşekkür}

Yazarlar, Sakarya Uygulamalı Bilimler Üniversitesi Biyomedikal Enstrümantasyon Laboratuvarı çalışanlarına ve öğrencilerine katkılarından dolayı minnettarlar. Bu çalışma ayrıca Sakarya Üniversitesi Girişimsel Olmayan Araştırmalar Etik Kurulu tarafından kabul edilmiş̧ir (no.71522473/050.01.04/341).

\section{Referanslar}

[1] J. M. Cross and C. L. Smith, "Thermographic imaging of the subcutaneous vascular network of the back of the hand for biometric identification", Proceedings of 29th International Carnahan Conference on Security Technology, Institute of Electrical and Electronics Engineers, 20-35, 1995.

[2] Sang-Kyun Im, Hyung-Man Park, Young-Woo Kim, Sang-Chan Han, Soo-Won Kim, ChulHee Kang and Chang-Kyung Chung, "An Biometric identification system by extracting hand vein patterns", Journal of the Korean Physical Society, 38(3): 268-272, March 2001. 
[3] Yildiz, Mustafa Zahid, and Ömer Faruk Boyraz. "Development of a low-cost microcomputer based vein imaging system." Infrared Physics \& Technology 98, 27-35, 2019.

[4] Yildiz, M. Z., Boyraz, O. F., Guleryuz, E., Akgul, A., \& Hussain, I. A Novel Encryption Method for Dorsal Hand Vein Images on a Microcomputer. IEEE Access, 7, 60850-60867, 2019.

[5] Z. Lu, S. Ding, and J. Yin, "Finger vein recognition based on finger crease location,” Journal of Electronic Imaging, vol. 25, no. 4, p. 043004, Nov. 2016.

[6] X. K. Lan, P. Chen, Z. H. Sun, and Z. X. Chen, "A palm vein acquisition and extraction system for personal authentication based on FPGA," Computer Science and Systems Engineering, Jan. 2015.

[7] R. Raghavendra and C. Busch, "A low cost wrist vein sensor for biometric authentication," 2016 IEEE International Conference on Imaging Systems and Techniques (IST), 2016.

[8] M. Akhloufi and A. Bendada, "Hand and Wrist Physiological Features Extraction for near Infrared Biometrics," 2008 Canadian Conference on Computer and Robot Vision, 2008.

[9] J. E. S. Pascual, J. Uriarte-Antonio, R. Sanchez-Reillo, and M. G. Lorenz, "Capturing Hand or Wrist Vein Images for Biometric Authentication Using Low-Cost Devices,” 2010 Sixth International Conference on Intelligent Information Hiding and Multimedia Signal Processing, 2010.

[10] O. C. Kurban, O. Niyaz, and T. Yildirim, "Neural network based wrist vein identification using ordinary camera," 2016 International Symposium on Innovations in Intelligent Systems and Applications (INISTA), 2016.

[11] Boyraz, Ömer Faruk, and Mustafa Zahid Yildiz. "Mobil Damar Görüntüleme Cihazı Tasarımı." 4th International Symposium on Innovative Technologies in Engineering and Science (ISITES2016) 3-5 Nov 2016 Alanya/Antalya-Turkey. 2016.

[12] H. Bay, T. Tuytelaars, and L. V. Gool, "SURF: Speeded Up Robust Features," Computer Vision - ECCV 2006 Lecture Notes in Computer Science, pp. 404-417, 2006. 